\title{
Interseccionalidades, categorias de articulação e experiências de migrantes brasileiras
}

\author{
Adriana Piscitelli \\ Doutora em Ciências Sociais - Unicamp \\ Pesquisadora do Pagu - Unicamp \\ adriana.piscitelli@pq.cnpq.br
}

\begin{abstract}
Resumo Neste texto apresento alguns comentários sobre o surgimento de categorias que aludem à multiplicidade de diferenciações que, articulando-se a gênero, permeiam o social. São as categorias de articulação e/ou as interseccionalidades (intersectionalities). Analiso o conteúdo atribuído a esses conceitos e considero como eles contribuem para analisar uma problemática relevante no Brasil contemporâneo: a feminização da migração internacional. Na primeira parte do artigo, situo a emergência desses conceitos no marco da história do pensamento feminista. Na segunda parte, considero como suas utilizações adquirem conotações distintas no que se refere à conceitualização das diferenças, das maneiras como o poder opera e das margens de agência (agency) concedidos aos sujeitos em distintas abordagens teóricas. Finalmente, na terceira parte, reflito sobre esses conteúdos levando em conta aspectos vinculados à integração de migrantes brasileiras no mercado global de trabalho e no mercado matrimonial.
\end{abstract}

Palavras-chave: interseccionalidades; gênero; feminismo; migração; mercado global de trabalho; mercado matrimonial.

\section{Introdução}

$\mathrm{N}$ ESTe texto trato De COnCeitos que estão adquirindo centralidade no debate feminista. O pensamento feminista, expressão de idéias que resultam da interação entre desenvolvimentos teóricos e práticas políticas, está longe de constituir um todo unificado. Na história desse pensamento, algumas categorias ou conceitos foram particularmente relevantes em momentos específicos. Nas diferentes perspectivas que o integram, conceitos elaborados em certas épocas têm persistido ao longo do tempo. Entretanto, é possível aludir a momentos, caracterizados pela relevância concedida a algumas conceitualizações.

No debate internacional, o final da década de 1990 está marcado pela emergência de categorias que aludem à multiplicidade de diferenciações que, articulando-se a gênero, permeiam o social. São as categorias de articulação e as interseccionalidades (intersectionalities). Algumas autoras optam por um desses conceitos (McKlintock, 1995; Crenshaw, 2002). Outras utilizam alternativamente ambos (Brah, 2006). Na década de 2000, a utilização dessas categorias está amplamente difundida. Contudo, assim como aconteceu com o conceito de gênero, essas categorias adquirem conteúdos diferentes segundo as abordagens teóricas das autoras que com elas trabalham.

Nesse texto apresento alguns comentários sobre o surgimento e o conteúdo atribuído a esses conceitos - categorias de articulação e in- 
terseccionalidades - e considero que algumas de suas vertentes contribuem para analisar uma problemática relevante no Brasil contemporâneo: a feminização da migração internacional. Na primeira parte do artigo, situo a emergência desses conceitos no marco da história do pensamento feminista. Depois considero como suas utilizações adquirem conotações distintas no que se refere à conceitualização das diferenças, das maneiras como o poder opera e das margens de agência (agency) concedidos aos sujeitos em distintas abordagens teóricas. Finalmente, reflito sobre esses conteúdos levando em conta aspectos vinculados à integração de migrantes brasileiras no mercado global de trabalho.

\section{Debate feminista, gênero, diferenças e poder}

Para situar a emergência dessas categorias é importante pensar em um momento, no final da década de 1980. É o grande momento em que várias autoras, trabalhando no âmbito de diferentes tradições disciplinares, publicaram textos críticos sobre gênero que se tornaram referências clássicas nas discussões contemporâneas. Refiro-me a Scott (1988) entre as historiadoras, a Strathern (1988) na antropologia, a Haraway (1991) na história da ciência, a Butler (1990), na filosofia. Algumas dessas autoras esperavam, valendo-se do trabalho com gênero, produzir deslocamentos nos paradigmas disciplinares no marco dos quais trabalhavam.

Por que textos críticos? Porque essas obras questionaram os pressupostos embutidos nas primeiras formulações de gênero, as perspectivas sobre poder que estavam informando várias linhas de análises feministas e, também, a centralidade concedida ao gênero em termos das forças sociais que oprimem às pessoas.

A partir da segunda metade da década de 1970, o conceito de gênero, pensado como construção cultural e arbitrária, variável, de aspectos vinculados ao sexo biológico, tido como natural é imutável, tinha se difundido de maneira extraordinária. Esse conceito, pensado no marco da distinção entre sexo e gênero, era considerado como um avanço em relação à categoria mulher (Piscitelli, 2002). Os escritos críticos de finais da década de 1980, porém, questionaram os pressupostos presentes na distinção sexo/gênero. Um dos motivos foi a fixidez e unidade que essa distinção conferia às identidades de gênero, ao formular a existência de uma base biológica imutável que dividia a humanidade em dois sexos e, consequentemente, em dois gêneros. Outro dos aspectos problematizados foi a universalidade atribuída a essa distinção.

Embora as primeiras formulações da distinção entre sexo e gênero foram pensadas como alternativa possível ao trabalho com o conceito de Patriarcado, muitas te- óricas feministas explicavam a situação de subordinação das mulheres utilizando simultaneamente ambos conceitos. Vale lembrar que, embora o Patriarcado sempre seja considerado como sistema de dominação masculina, há diferenças entre as maneiras de concebê-lo em correntes feministas radicais e socialistas. Às primeiras atribui-se a disseminação da idéia de Patriarcado como sistemas de opressão presentes ao longo do tempo e mediante as culturas, implicando que, universalmente, as mulheres compartilham uma realidade separada dos homens. Nas correntes socialistas, o patriarcado adquire uma dimensão histórica (variando no tempo) e uma base material, intimamente ligado aos modos de produção e reprodução - embora sua existência em modos de produção muito diferentes evoque os pressupostos radicais sobre a dominação masculina transhistórica (Heinen, 2000; Grant, 1993; Mohanty, 1991).

Diversas autoras, porém, passaram a questionar o caráter transhistórico e/ou a fixidez desse conceito (Apfelbaum, 2000). Elas se perguntaram seriamente em que consistia a dominação masculina, como se media? Seria possível pensar essa dominação como universal? Seria possível considerar como equivalentes aspectos tais como o lugar das mulheres na divisão sexual do trabalho, sua desvalorização nos mitos ou o controle das mulheres mediante um estupro coletivo? (Rubin, 1975; Reiter, 1975).

Nos escritos críticos de finais da década de 1980 há sérias problematizações a noções correntes no pensamento feminista sobre as operações do poder, particularmente à universalização do quadro ideológico do poder e das relações de poder presentes no paradigma ocidental das relações de gênero. Algumas antropólogas chamaram a atenção para o fato de que a compreensão do gênero ocidental, incluindo o pensamento feministas, está ligada não apenas às relações entre os sexos, mas a idéias mais gerais sobre como a cultura é diferente de e superior à natureza. No centro desse paradigma haveria uma teoria do poder e o político, que inclui noções muito específicas sobre relações de dominação e subordinação, exploração, coerção, controle e desigualdade (Overing, 1986; Strathern, 1988). Essas autoras contestaram a universalidade da hierarquia e da subordinação feminina com base em leituras de sistemas nativos de moralidade e de concepções nativas do poder e o político. De acordo com elas, a dominância masculina, nos contextos nos quais ela se apresenta, não poderia ser universalmente pensada em termos da lógica ocidental, ancorada em pressupostos de propriedade, à maneira como se possui uma mercadoria.

Esses questionamentos foram realizados por meio de um deslocamento nos referenciais teóricos utilizados. As autoras passaram a se ancorar em aproximações desconstrutivistas. Refiro-me ao procedimento de olhar criticamente para os supostos sustentados por diversas disciplinas, examinando e desmontando sua lógica discursiva. A produção crítica sobre gêne- 
ro possibilita perceber uma convergência no que se refere a problematizar os modelos teóricos totalizantes. As autoras contestam a validade dos modelos que buscam analisar e explicar as transformações históricas pressupondo, por exemplo, a continuidade de certas estruturas e/ou instituições. Elas questionam, também, as abordagens que formulam uma compreensão da diferença tendo como referência um Outro exógeno, externo, procedimento que mantém o princípio de uma unidade e coerência cultural interna. Essas teóricas trabalham com a idéia de dissolução do sujeito universal autoconsciente; valorizam a linguagem e o discurso como práticas relacionais, que produzem e constituem as instituições e os próprios sujeitos como sujeitos históricos e culturais e compreendem, enfim, a produção de saber e significação como ato de poder (Bessa, 1995).

Nessa produção é visível a tendência a trabalhar com uma noção pulverizada de poder, à maneira de Foucault (1977). Um exemplo é oferecido por Joan Scott (1988) que, rejeitando a noção de Patriarcado, propõe explorar as distribuições diferenciadas de poder permeando contextos históricos específicos. Com esse objetivo, a autora propõe substituir a noção de que o poder social é unificado, coerente e centralizado por uma idéia de poder como constelações dispersas de relações desiguais.

\section{Diferença sexual e outras diferenças}

Essas leituras críticas do conceito de gênero, formuladas no plano teórico, coincidem com intensas reivindicações, internas ao movimento feminista, relativas à diferença, formuladas por mulheres negras, do Terceiro Mundo e por feministas lésbicas (Haraway, 1991). Entretanto, as reelaborações teóricas não incorporaram as exigências de prestar atenção a outras diferenças, para além da sexual, de maneira homogênea. Na história do pensamento feminista, a relação com outras diferenças têm sido tensa, uma vez que algumas correntes consideravam que dar peso a elas debilitava um pressuposto político relevante: a identidade entre mulheres. Os escritos críticos de finais da década de 1980 tendem a reconhecer essas diferenças. Entretanto, esse reconhecimento nem sempre se expressou no plano analítico e, quando ele existiu, muitas vezes privilegiou uma única diferença articulada a gênero ${ }^{1}$.

Algumas das autoras que se envolveram nas reformulações críticas do conceito de gênero enunciaram a importância de considerar conjuntamente classe, raça e gênero. Entretanto, elas continuaram privilegiando a categoria gênero. Joan Scott (1988), por exemplo, afirma que, como feminista, seu compromisso é, sobretudo, com o saber sobre a diferença sexual. Nesse sentido, segundo ela, com base em sua proposta analítica, seria possível fazer emergir uma nova história que redefiniria novas questões, em conjunção com uma visão da igualdade que também incluísse classe e raça. Entretanto, ela não faz uma tentativa maior de elaboração que articule essas diferenciações.

Outras autoras ratificam a importância de pensar em diversas categorias de diferenciação, contudo acabam prestando particular atenção à articulação entre algumas diferenças específicas. Uma delas é a relação entre gênero e sexualidade. Judith Butler, uma das críticas mais radicais do conceito de gênero, oferece um exemplo dessa posição.

A autora pensa gênero como o mecanismo segundo o qual se produzem e naturalizam noções do masculino e feminino, mas também como o mecanismo mediante o qual esses termos são desconstruídos e desnaturalizados (Butler, 2002). A radicalidade de sua formulação consiste em que gênero para ela é relacional, não no sentido de tratar-se de relações entre homens e mulheres, ou entre masculino ou feminino, mas porque pensa em gênero como um fazer, como uma atividade que é performada para alguém, mesmo que esse alguém seja inteiramente imaginário. Ela propõe afastar o gênero de idéias como a relação entre masculinidade e feminilidade, pois o binário mascu-

10 pensamento feminista vinculado ao marxismo e ao socialismo sempre levou em conta as diferenças de classe. Vale lembrar a força concedida a essa distinção nos escritos das primeiras décadas do século XX (Goldman, 1917) e também as infinitas discussões, no âmbito do feminismo da "segunda onda", durante a década de 1970, entre as radicais que concediam primazia ao patriarcado e as socialistas, que se centravam na articulação entre patriarcado e capitalismo, prestando séria atenção às diferenças de classe entre as mulheres (Beechey, 1979). O feminismo radical da segunda onda, ao contrário, caracterizou-se por minimizar diferenças que não fossem as sexuais, às quais conferiam absoluta primazia. Assim, as discriminações vinculadas à classe e raça não encontravam abrigo nessas formulações. Nesse sentido, são significativos os comentários de Shulamith Firestone (1976), no que se refere ao racismo. A autora afirma que o racismo está limitado ao âmbito da cultura ocidental. Mas, a luta das feministas deveria ir além dessa cultura específica, questionando a própria organização da cultura e da natureza, nas quais se ancora a desigualdade das mulheres. Essas idéias são relevantes porque remetem à centralidade concedida à diferença sexual, em termos universais, por algumas correntes do pensamento feminista. Observe-se, porém, que a raça é tratada como se apenas oferecesse elementos para estabelecer analogias, comparações entre formas de opressão, em diversas formulações feministas. Neste sentido, vale a pena prestar atenção à maneira como Gayle Rubin (1975) trata das diferenças raciais. Quando a autora formula a idéia de sistema de sexo e gênero, estabelece paralelismos entre diferentes movimentos de oprimidos que deveriam unir-se: feministas; negros americanos; pessoas do terceiro mundo; indígenas americanos, mas não há tentativas de articular as diferenças nas quais se ancoram essas opressões. 
lino/feminino não esgotaria o campo semântico do gênero. Em um diálogo múltiplo com aspectos do pensamento feminista, do pensamento queer e com os movimentos da Nova Política do Gênero que reivindicam direitos sexuais, incluindo os direitos de pessoas intersex e trans, a autora afirma que a existência de transgêneros sugere que o gênero se desloca além desse binarismo naturalizado.

No que se refere à relação entre gênero, sexualidade e raça, Butler assume uma posição ambígua. Ela afirma reiteradamente a necessidade de analisar essa relação. Em Gender Trouble (1990) alega que gênero estabelece interseções com modalidades raciais, classistas, étnicas, sexuais e regionais de identidades discursivamente constituídas. Essas interseções não poderiam ser hierarquizadas nos termos de alguma condição primária de opressão. Contudo, ela só realiza uma tentativa de análise articulando esse conjunto de diferenças em um capítulo de uma obra posterior, Bodies that Matter (1993).

Nesse livro, a autora considera sexo e raça como efeito de regimes de produção reguladora que operam na produção dos contornos corporais. Além de contestar a idéia de que a diferença sexual seja a diferença da qual podem ser derivadas as outras diferenças, Judith Butler afirma que a reprodução da heterossexualidade assume formas diferentes segundo como se entendam a raça e a reprodução da raça. Entretanto, excetuando o capítulo mencionado desse livro, os restantes lidam exclusivamente com sexualidade e gênero, que certamente é a articulação central para a autora. Não é por acaso que toda a sua formulação sobre a abjeção, designando as zonas inabitáveis da vida social, está ancorada na relação entre gênero e sexualidade, na produção dos gêneros não inteligíveis que desestabilizam a harmonia binária e linear entre sexo, gênero e desejo.

Outras autoras privilegiaram a articulação entre raça e gênero, em linhas de discussão que denunciam as exclusões do pensamento feminista da segunda onda, que já não é mais pensado apenas como pensamento feminista, mas como pensamento feminista branco (Bhavnani, 2001; Haraway, 1991). Nessa discussão, algumas teóricas questionam, com base em experiência como mulheres negras em contextos marcados pelo racismo, a centralidade concedida à sexualidade como diferença em algumas linhas do pensamento feminista (Amos e Parmar, 1984). Nessa linha de debate, há autoras que chegam até mesmo a privilegiar, a priori, a raça entre outras diferenças possíveis (Baca Zinn/Dill, 1996).

As insatisfações com a centralidade concedida à categoria gênero suscitaram ainda outras problematizações. As feministas do Terceiro Mundo e/ou que trabalham com teoria pós-colonial chamaram a atenção para a necessidade de articular gênero não apenas a sexualidade, raça, classe, mas também a religião e nacionalidade (Shohat, 1992; MacKlintock, 1992; Mohanty, 1991). Com esse último termo elas aludiam ao posicionamento desigual, em escala global, propiciado pela nacionalidade. Isso que, à falta de um nome melhor, chamo de localização, para aludir à posição estrutural das nacionalidades que estão interagindo.

Finalmente, outras autoras concedem relevância à análise conjunta de uma constelação de diferenças. No entanto, consideraram que para analisar de maneira adequada a operação conjunta dessas diferenças é necessário criar categorias alternativas a gênero e também à raça. Donna Haraway, bióloga e historiadora da ciência, oferece um exemplo dessa posição.

Segundo ela, ao insistir no caráter de construção social do gênero, nem o sexo nem a natureza foram historicizadas e, com isso, ficaram intactas idéias perigosas relacionadas com identidades essenciais tais como mulheres ou homens. Ela considera que, trabalhando com a distinção sexo/gênero, seria impossível desconstruir como os corpos, sexualizados e racializados, aparecem como objetos de conhecimento e espaços de intervenção na biologia. E, sobretudo, considera que a centralidade concedida à categoria gênero obscurece ou subordina todas as outras, como raça e classe, outras, que emergem nitidamente das 'políticas da diferença', em um movimento imperalista do feminismo branco e ocidental.

Como saída, ela propõe trabalhar com um conceito diferente, os aparatos de produção corporal, que historicizando categorias como sexo, carne, corpo, biologia, raça e natureza, permitiria pensar na emergência de corpos marcados por diferenças, em uma perspectiva na qual a natureza não fosse imaginada como um recurso para a cultura, ou como o sexo para o gênero.

Os questionamentos presentes nas formulações dessas autoras continuaram sendo elaborados com intensidade durante a década de 1990, sob a intensa pressão dos movimentos políticos. No bojo desse movimento, na procura de categorias analíticas alternativas, surge a formulação dos conceitos categorias de articulação e/ou interseccionalidades.

\section{Interseccionalidades e/ou categorias de articulação}

A proposta de trabalho com essas categorias é oferecer ferramentas analíticas para apreender a articulação de múltiplas diferenças e desigualdades. É importante destacar que já não se trata da diferença sexual, nem da relação entre gênero e raça ou gênero e sexualidade, mas da diferença, em sentido amplo para dar cabida às interações entre possíveis diferenças presentes em contextos específicos. 
O debate sobre as interseccionalidades permite perceber a coexistência de diversas abordagens. Diferentes perspectivas utilizam os mesmos termos para referir-se à articulação entre diferenciações, mas elas variam em função de como são pensados diferença e poder. Essas abordagens divergem também em termos das margens de agência (agency) concedidas aos sujeitos, isto é, as possibilidades no que se refere à capacidade de agir, mediada cultural e socialmente.

Essas discordâncias podem ser percebidas contrapondo as formulações de autoras relevantes no debate. Uma delas é Kimberlé Crenshaw, cujos textos se tornaram leitura obrigatória na primeira metade da década de 1990. A revista Estudos Feministas (2002) publicou em português seu Documento para o encontro de especialistas em aspectos da discriminação racial relativos ao gênero. A autora é uma advogada que procura oferecer elementos para formular políticas com o objetivo de evitar a violação dos direitos humanos das mulheres, em escala global.

\section{Kimberlé Crenshaw - leituras sistêmicas}

Segundo Crenshaw, as interseccionalidades são formas de capturar as conseqüências da interação entre duas ou mais formas de subordinação: sexismo, racismo, patriarcalismo. Essa noção de 'interação' entre formas de subordinação possibilitaria superar a noção de superposição de opressões. Por exemplo, a idéia de que uma mulher negra é duplamente oprimida, à opressão por ser mulher deve ser adicionada a opressão por ser negra. A interseccionalidade trataria da forma como ações e políticas específicas geram opressões que fluem ao longo de tais eixos, confluindo e, nessas confluências constituiriam aspectos ativos do desempoderamento. A imagem que ela oferece é a de diversas avenidas, em cada uma das quais circula um desses eixos de opressão. Em certos lugares, as avenidas se cruzam, e a mulher que se encontra no entrecruzamento tem que enfrentar simultaneamente os fluxos que confluem, oprimindo-a.

Essa formulação retoma a idéia de patriarcado. $\mathrm{Na}$ verdade, a linguagem parece remeter aos textos da década de 1970: patriarcalismo, experiência, subordinação. Diferentemente das formulações feministas da segunda onda, porém, na elaboração de Crenshaw, gênero não é o único fator de discriminação. Outros fatores estão operando conjuntamente. A autora utiliza reiteradamente termos como vulnerabilidade, desempoderamento, o que faz sentido quando se pensa em seu objetivo. Os exemplos que ela oferece são extremos, como os estupros coletivos, por motivos étnicos, em Ruanda e na Bósnia, ou a situação das mulheres de castas inferiores na Índia. As mulheres dalit, espancadas em espaços públicos quando realizam suas responsabilidades femininas, como buscar água na fonte. Os abusos ocorrem em contextos em que a suposta condição de intocável as deixa vulneráveis à violência das castas mais altas. Essa violência não seria apenas discriminação de casta, mas intersecional. Segundo a autora, as mulheres estão situadas em uma posição na qual as responsabilidades marcadas por gênero as posiciona de forma que elas absorvam as conseqüências da discriminação de casta na esfera pública (Crenshaw, 2002).

Uma das minhas principais questões em relação à generalização dessa abordagem, pensada para casos de graves violações dos direitos humanos, é que, em uma perspectiva antropológica, essa formulação apresenta uma séria fragilidade: ela funde a idéia de diferença com a de desigualdade. As leituras críticas sobre interseccionalidade consideram essa leitura de Crenshaw expressiva de uma linha sistêmica, que destaca o impacto do sistema ou a estrutura sobre a formação de identidades. Nesse sentido, problematizam outros aspectos dessa formulação. Questionam o fato de que gênero, raça e classe são pensados como sistemas de dominação, opressão e marginalização que determinam identidades, exclusivamente vinculadas aos efeitos da subordinação social e o desempoderamento (Prins, 2006).

Outro problema apontado nessa abordagem é que nela o poder é tratado como uma propriedade que uns têm e outros não, e não como uma relação. De acordo com Baukje Prins (2006), as linhas que se inserem no enfoque sistêmico sobre interseccionalidades às vezes trabalham com o referencial oferecido por Foucault, mas utilizam seletivamente sua noção de poder. Elas ignorariam o fato de que esse autor pensa em poder não apenas em sentido repressivo, mas também produtivo, que não apenas suprime, mas produz sujeitos. Finalmente, não consideram que as relações de poder se alteram constantemente, marcadas por conflitos e pontos de resistência.

\section{Anne McKlintock e Avtar Brah - abordagens construcionistas}

Uma segunda linha de abordagem, denominada pela autora de construcionista, destaca, sobretudo, os aspectos dinâmicos e relacionais da identidade social. Nessa abordagem são marcantes a visão de poder de Gramsci, em termos de lutas contínuas em torno da hegemonia, e o trabalho com a noção de articulação entendida como prática que estabelece uma relação entre elementos, de maneira que sua identidade se modifica como resultado da prática articulatória. Nes- 
sa abordagem se traçam distinções entre categorias de diferenciação e sistemas de discriminação, entre diferença e desigualdade. Por exemplo, há um questionamento à fusão entre raça e racismo, considerando que nessa fusão há uma visão estática do significado da categoria raça e se trata o racismo como um sistema único.

De acordo com Prins (2006), na primeira linha de abordagem (sistêmica), a agência não é negada aos sujeitos. A idéia é contribuir para o empoderamento dos grupos subordinados. Entretanto, a interseccionalidade aparece voltada para revelar o poder unilateral das representações sociais e as conseqüências materiais e simbólicas para os grupos atingidos pelos sistemas de subordinação. Os sujeitos aparecem como constituídos por sistemas de dominação e marginalização e, nesse sentido, carentes de agência. $\mathrm{Na}$ segunda linha de abordagem (construcionista), os processos mediante os quais os indivíduos se tornam sujeitos não significam apenas que alguém será sujeito a um poder soberano, mas há algo mais, que oferece possibilidades para o sujeito. E os marcadores de identidade, como gênero, classe ou etnicidade não aparecem apenas como formas de categorização exclusivamente limitantes. Eles oferecem, simultaneamente, recursos que possibilitam a ação.

Nesta segunda linha podemos situar autoras como McKlintock (1995) e Brah (2006). A primeira delas, no marco dos estudos culturais, em Estados Unidos, analisa o poder imperial afirmando que raça, gênero e classe não são âmbitos diferentes de experiência que existem isoladamente uns dos outros, nem podem ser simplesmente montados em conjunto como se fosse um lego. Essas categorias existem em e por meio das relações entre elas. Por esse motivo são categorias articuladas. As categorias de diferenciação não são idênticas entre sim, mas existem em relações, íntimas, recíprocas e contraditórias. Nas encruzilhadas dessas contradições é possível encontrar estratégias para a mudança. A articulação seria perceptível ao considerar como, no âmbito imperial, gênero está vinculado à sexualidade, mas também ao trabalho subordinado e raça é uma questão que vai além da cor da pele, incluindo a força de trabalho, atravessada por gênero. Ao analisar as categorias articuladas, McKlintock explora políticas de agência diversificadas, que envolvem coerção, negociação, cumplicidade, recusa, mimesis, compromisso e revolta.

A noção de articulação e uma leitura ampla das políticas de agência estão presentes também no trabalho Brah (2006), que rejeita o conceito de patriarcado, preferindo pensar em relações patriarcais nos casos específicos em que as mulheres ocupam posições subordinadas. Essa autora, após uma trajetória marcada pelo deslocamento por diversos contextos, se envolveu com o trabalho com a articulação entre gênero, raça, etnicidade e sexualidade, no feminismo negro, na Inglaterra ${ }^{2}$. A autora publicou um livro, em 1996, Cartographies of Diaspora, que se tornou uma referência, um de cujos capítulos foi traduzido nos Cadernos PAGU (2006). Nesse livro, faz uma série de formulações inovadoras no seio do movimento feminista. Em algumas dessas formulações ela segue Hall (1996) ${ }^{3}$. Entretanto, diferentemente dele, ela se situa no bojo da discussão do feminismo negro e concede um lugar relevante a gênero.

A autora propõe uma análise macro, considerando simultaneamente subjetividade e identidade para compreender as dinâmicas de poder na diferenciação social. Este é um aspecto característico das feministas do Terceiro Mundo e que trabalham como teorias pós-coloniais, porque as preocupações políticas que as orientam requerem que as análises compreendam a produção de subjetividades no marco da história do imperialismo e do capitalismo. Avtar Brah levanta vários pontos importantes.

2 Avtar Brah nasceu na Índia, cresceu em Uganda de onde fugiu com a família antes que Idi Amin expulsasse os asiáticos do país, estudou nos Estados Unidos e morou depois na Inglaterra, onde se envolveu nos movimentos feministas, anti-racistas e nas tentativas socialistas de imaginar um mundo democrático.

3 Hall (1996) estava interessado em entender as relações entre classe social e racismo em um momento no qual considerava não existir elementos teóricos que possibilitassem fazê-lo. Trabalhando com tradições marxistas e seguindo Foster Carter, explora as possibilidades das categorias de articulação. A articulação seria uma metáfora utilizada para indicar relações de conexões e eficácia entre diferentes níveis de todo tipo de coisas. Essas coisas estariam conectadas, mas não haveria uma identidade entre elas. A unidade formada por essa articulação é uma estrutura complexa que as relaciona por suas diferenças e semelhanças. Segundo Hall, o importante é desvendar qual é o mecanismo que conecta as coisas e a natureza das relações entre as partes. Considerando que o econômico não determina outros níveis da formação social nem sua forma de operação, Hall afirma que ao analisar as relações entre diversos níveis de uma formação social, seriam necessários outros conceitos, além dos níveis econômicos do modo de produção. O autor recorre também a Gramsci, particularmente ao conceito de hegemonia, como estado de total autoridade social que em conjunturas específicas possibilita o domínio de uma classe sobre toda uma formação social, por uma mistura de coerção e consentimento, não apenas no nivel econômico, mas também político e ideológico, na vida civil, intelectual e moral assim como no aspecto material. Mas, essa autoridade está sujeita a relações de forças sociais, das quais o equilibrio instável é um resultado provisório. Para sustentar-se, a hegemonia exige ser continuamente trabalhada e reconstruída. A luta de classes não assumiria a forma de um ataque frontal, mas de lugares estratégicos, tácticas, explorando diferentes contradições. E o que interessa seria entender como as ideologias existentes, que são contraditórias, podem ser trabalhadas para transformar-se na base de uma luta mais consciente, uma form de intervenção no processo histórico. 
A autora afirma que a procura de grandes teorias especificando as interconexões entre racismo, gênero e classe tem sido pouco produtiva. Essas interconexões seriam melhor compreendidas como relações contextuais e dependentes/contingentes (contingents), em termos históricos. Ela considera que analisar as interconexões entre racismo, gênero, classe, sexualidade etc. requer levar em conta a posição de diversos racismos, um em relação aos outros. No que se refere aos processos de racialização, assinala que não sempre têm lugar em uma matriz simples de bipolaridades, de negatividade ou positividade, de inclusão ou exclusão. Em um contexto racializado, todas as sexualidades estão inscritas em matrizes racializadas de poder, mas os encontros racializados também têm lugar em espaços de profunda ambivalência, admiração, inveja, desejo.

A proposta de Avtar Brah é trabalhar, não com gênero como categoria analítica, como, por exemplo, Scott, mas com 'diferença' como categoria analítica. Essa idéia remete à análise de como as formas específicas de discursos sobre a diferença se constituem, são contestados, reproduzidos e (re)significados, pensando na diferença como experiência, como relação social, como subjetividade e como identidade. A autora afirma que há discursos que apresentam diferenças, como o racismo, que traçam limites fixos. Entretanto, outras diferenças podem ser apresentadas como relacionais, contingentes. Como a diferença nem sempre é um marcador de hierarquia nem de opressão, uma pergunta a ser constantemente feita é se a diferença remete à desigualdade, opressão, exploração. $\mathrm{Ou}$, ao contrário, se a diferença remete a igualitarismo, diversidade, ou a formas democráticas de agência política.

Algumas discussões sobre interseccionalidade consideram que essa conceitualização é problemática porque coloca excessiva ênfase nos eixos classificatórios não prestando suficiente atenção à experiência. Assim, poderia ser pensado que o trabalho com categorias de articulação se diferencia da análise das interseccionalidades, pois as autoras que trabalham com categorias articuladas concedem lugar de destaque à experiência. Contudo, nesse debate as visões sobre diferença, poder e agência presentes nas diversas abordagens são mais importantes do que os termos que designam esses conceitos (interseccionalidade ou categorias de articulação). Brah (2006; 2004), por exemplo utiliza alternativamente a idéia de categorias de articulação e de interseccionalidades.

Essa última linha de pensamento sobre a interseção entre diferenciações é sugestiva para pensar como construções de diferença e distribuições de poder incidem no posicionamento desigual dos sujeitos no âmbito global. Tomo como exemplo as recentes migrações internacionais de mulheres brasileiras, e como as percepções sobre essas migrantes incidem em suas inserções no mercado global de trabalho e no mercado matrimonial.

\section{Brasileiras no cenário global}

A experiência de migrantes (e viajantes) brasileiras é afetada por aspectos que não podem ser compreendidos considerando uma ou duas categorias de diferenciação, tais como gênero e nacionalidade, por exemplo. Esclareço que estou pensando, à maneira de Scott (1998), não em indivíduos 'que têm' experiências, mas em 'sujeitos constituídos mediante a experiência'. Essas migrantes são afetadas pela imbricação entre noções de sexualidade, gênero, raça, etnicidade e nacionalidade. Refirome às noções sexualizadas e racializadas de feminilidade pelo fato de serem brasileiras. Independentemente de serem consideradas no Brasil, brancas ou morenas, nos fluxos migratórios para certos países do Norte as brasileiras são racializadas como mestiças. No lugar desigual atribuído ao Brasil no âmbito global, a nacionalidade brasileira, mas do que a cor da pele, confere-lhes essa condição. E essa racialização é sexualizada. Nos últimos anos, o fato de o Brasil ter sido incluído nos circuitos mundiais de turismo sexual e das brasileiras adquirirem visibilidade na indústria do sexo em países dos Sul da Europa, tem acentuado essas relações entre categorias no cenário global (Piscitelli, 2004; 2007).

A maioria das brasileiras que viaja não tem vinculação com esse setor de atividade. Entretanto, essa articulação entre marcadores de diferença é ativada independentemente de que as mulheres estejam ou não vinculadas à indústria do sexo. A idéia de que elas são portadoras de uma disposição naturalmente intensa para fazer sexo e uma propensão à prostituição, combinadas com noções ambíguas sobre seus estilos de feminilidade, tidos como submissos, com uma alegre disposição para a domesticidade e a maternidade tende a atingir indiscriminadamente essas migrantes.

Essas conceitualizações variam, claro, em contextos migratórios que têm diferentes relações históricas com o Brasil e também de acordo com a classe social e, em certos casos, a cor das mulheres (quando fenotipicamente não são percebidas como mestiças/ mulatas, mas como negras). No entanto, nos fluxos para países ricos da América do Norte e Europa, a tradução cultural da posição subalterna ocupada pelo Brasil nas relações transnacionais é um dos aspectos principais que afetam as experiências dessas mulheres. E essa tradução é realizada mediante uma articulação entre diferenciações. 
Em termos de migração internacional, Brasil foi considerado um país predominantemente receptor em um passado muito recente ${ }^{4}$. Na década de 1980, pela primeira vez, no contexto de uma séria crise econômica, o país apresentou uma emigração significativa. A partir de então, a falta de oportunidades laborais e de possibilidade de mobilidade social, sobretudo para alguns setores das classes médias, alimentaram os fluxos de migração ao exterior.

Em 2006, relatórios do governo estimavam que em torno de 3.000.000 de brasileiros estavam morando no exterior, (1,7 \% do total da população)(Magno, 2006) $)^{5}$. Parte significativa desse contingente vive como irregular fora, e isso torna difícil ter estatísticas precisas. A escassa atenção prestada ao sexo ao coletar os dados coloca ainda maiores dificuldades para estimar o número de mulheres migrantes no exterior. Entretanto, o deslocamento das mulheres aparece como significativo. De acordo com dados da Polícia Federal Brasileira, em 2005 elas constituíam em torno de 30\% do total de pessoas devolvidas de países estrangeiros, incluindo deportadas e uma vasta maioria de mulheres não admitidas, cujo ingresso é recusado em países que não requerem vistos de turistas brasileiros, especialmente nos aeroportos europeus.

Recentes relatórios governamentais sugerem que a maioria das mulheres deportadas é de classe média baixa. Trata-se, majoritariamente de solteiras ou divorciadas na casa dos 20 e 30 anos, a metade tem filhos e se consideram majoritariamente morenas ou pardas (Secretaria Nacional de Justiça 2006; 2005). As motivações econômicas aparecem como a principal razão para migrar, seja em razão de estratégias familiares ou pessoais. Contudo, esses perfis não podem ser generalizados. Pesquisas sobre migrantes internacionais brasileiras apontam para uma diversificação em termos das origens de classe, escolaridade e cores da pele. Esses aspectos interferem na inserção social dessas mulheres em suas trajetórias migratórias.

Em diferentes contextos migratórios, as brasileiras trabalham no comércio, em serviços administrativos, educacionais e de saúde e também como peque- nas empresárias (Cavalcanti, 2006). Entretanto, como outras mulheres do Terceiro Mundo, desempenham atividades especialmente em serviços domésticos: limpando, cuidando de crianças ou idosos (Oliveira, 2006; Messias, 2001). E, particularmente em países do Sul da Europa, também trabalham na indústria do sexo (Mayorga 2006; Piscitelli, 2007). Apesar de que apenas uma parte das brasileiras está ocupada nesse setor, a relevância dessa atividade é amplificada por uma cobertura de imprensa que freqüentemente funde os deslocamentos internacionais para trabalhar na indústria do sexo com o tráfico internacional de pessoas.

A presença feminina é particularmente relevante nas comunidades brasileiras nos países do Sul da Europa. Em 2006, elas eram em torno do 60\% na Espanha e aproximadamente metade da população brasileira vivendo em Portugal (Instituto Nacional de Estadística, 2006; Serviço de Estrangeiros e Fronteiras, 2005). Nesses países, assim como na Itália, as brasileiras são consideradas uma presença relevante na indústria do sexo e também integram os principais contingentes de esposas estrangeiras casadas com homens nacionais. E, nesses países, os escassos casamentos transnacionais envolvendo homens brasileiros sugerem que as mulheres adquirem um valor particular no mercado matrimonial ${ }^{6}$. Ter ou não visto de permanência, direito a trabalhar legalmente, oportunidades laborais, casar com homens residentes dos países receptores e ter filhos nos contextos migratórios são aspectos que marcam diferenças significativas nas experiências dessas migrantes brasileiras.

Afirmar que mulheres de diversas origens de classe e níveis de escolaridade são afetadas pela recriação de imagens racializadas e sexualizadas vinculadas a estilos de feminilidade brasileiros requer considerar dois aspectos. Embora as mulheres de países do Sul estejam confinadas em ocupações específicas, elas não constituem um todo homogêneo nos países de origem nem nos de destino. No marco das desigualdades entre Norte e Sul, essas diferenças são freqüentemente traduzidas por fronteiras etno-sexuais (Nagel, 2003), delimitações traçadas na interação entre sexualidade e etnicidade que, de acordo

4 De acordo com os estudos sobre migração, entre a década de 1890 e a Primeira Guerra Mundial, Brasil era o terceiro país receptor em América, depois dos Estados Unidos e Argentina, recebendo imigrantes, sobretudo, de Itália, Portugal e Espanha (Menezes 2001 ). Entre 1908 e 1940 houve também fluxo significativos de japoneses e de cidadões de outros países europeus (Seyferth 2001). No momento atual, o país recebe, sobretudo, imigrantes de outros países latino-americanos.

5 Segundo o Relatório final da Comissão Parlamentar de Inquérito de Emigração, em 2006, os principais países receptores eram Estados Unidos (1,800,000), Paraguai (450,000), Japão (250,000), Portugal $(100,000)$, Reino Unido $(100,000)$. Nos últimos três anos, os migrantes brasileiros cresceram rapidamente em algumas partes do mundo, particularmente nos países do Sul da Europa. Desde 2005 México exige visto dos cidadãos brasileiros, dificultando o acesso à fronteiras dos Estados Unidos. Os efeitos dessa exigência são o aumento nas vinculações transnacionais entre os traficantes de migrantes e a elevação dos custos e o aumento dos riscos dessas viagens ao tentar atravessar clandestinamente mais de uma fronteira. Como resultado, o fluxo migratório voltado para os países europeus tem aumentado (Secretaria Nacional de Justiça, 2007). Agentes consulares na Espanha e a Itália afirmam estar oferecendo serviços a um número muito mais elevado de brasileiros que três anos atrás. (Piscitelli 2005; 2007).

6 Em 2006 as brasileiras integravam o Segundo coletivo nacional de estrangeiras que casaram com homens espanhóis (Instituto Nacional de Estadística 2006; 2005). Na Itália, de acordo com as analises do censo de 2001, Brasil foi o principal país latino-americano que forneceu esposas aos italianos. Istituto Nazionale de Statistica: Gli stranieri in Italia: analisi dei dati censuari, 2005. In: www.istat.it. 
com o contexto, afetam mulheres de regiões e países de maneiras diferenciadas. Tendo como referência a posição ocupada pelas mulheres latino-americanas nos Estados Unidos, seria possível pensar que as tropicalizações (Aparicio; Chávez-Silverman, 1997), imagens sexualizadas e racializadas associadas aos trópicos, impingem em qualquer mulher dessa região do mundo.

Estudos realizados nos Estados Unidos e em países do Sul da Europa mostram, porém, que essas noções tropicalizadas de feminilidade afetam, sobretudo, mulheres de certos países. Trata-se de países como Brasil, Cuba e Colômbia, associados com misturas raciais que evocam misturas raciais, particularmente, com traços africanos. O serviço doméstico e de cuidados absorve latino-americanas de diversas nacionalidades. Entretanto, nos países do Sul da Europa, cubanas, colombianas e brasileiras são as mulheres que adquirem visibilidade nos mercados do sexo e matrimonial. Nos processos de racialização que as atingem há, às vezes, um racismo aberto. No entanto, e aqui vale a pena lembrar a relevância que Avtar Brah concede à interação entre racismos, nos países do Sul da Europa, o racismo atinge com mais suavidade as brasileiras, particularmente as que não são vistas como negras, que a mulheres de outras nacionalidades.

A interseção entre nacionalidade, gênero e sexualidade e o particular estilo de racialização permeado por essas diferenças incide em um racismo etnicizado, distante da intensidade daquele que atinge, entre as latinoamericanas, a mulheres tidas como negras e àquelas cuja nacionalidade é associada a traços considerados indígenas e pouco sensualizados. Essas últimas não integram as comunidades nacionais nas quais os homens nativos escolhem esposas.

Os efeitos dessas noções são mais atenuados entre mulheres que obtêm melhores posições, em termos de classe, nos países receptores. No entanto, brasileiras de diversas origens são afetadas por essas idéias. A relação dessas migrantes com a articulação entre diferenças que as sexualiza e racializa não é estável. Há movimentos de resistência e rejeição. Entretanto, situacionalmente, também assumem posições de cumplicidade utilizando aspectos das imagens sobre elas para negociar seus posicionamentos nos contextos migratórios nos quais estão em situação de desigualdade. É um jogo que reforça certos estereótipos ao passo que debilita outros. Tanto no mercado de trabalho como no mercado de casamento as conexões da feminilidade brasileira com a idéia de serem amigáveis, de terem um compromisso com a domesticidade, de serem muito limpas e de terem uma natural propensão para o cuidado e também para a sensualidade, se tornam parte do arsenal que essas mulheres utilizam na luta por um lugar melhor nesses cenários (Pinto 2004; Beserra, 2007; Piscitelli, 2005).

Essas negociações são descritas em estudos realizados em Boston, que mostram como alguns desses atributos são utilizados para obter, por exemplo, acesso a níveis privilegiados de trabalho doméstico pago (Assis, 2004). A suposta abertura das brasileiras, sua alegria e propensão ao cuidado são exibidos para atrair clientes para suas próprias firmas de limpeza. Esses atributos étnicos são ativados para abrir firmas, nas quais muitas vezes elas são as chefes dos homens de suas redes de parentesco. Esses trabalhos alteram as dinâmicas de gênero familiares e oferecem a essas mulheres o que elas consideram como uma atividade autônoma e bem paga.

Em diversos meios, as migrantes brasileiras rejeitam abertamente a conexão entre sensualidade e brasilidade. Ao mesmo tempo, em certas situações essa conexão aparece como sendo estrategicamente performada. O sex appeal étnico é utilizado como um bem por mulheres que trabalham na indústria do sexo, que acreditam que é útil para atrair clientes. No entanto, esse sex appeal também é percebido como oferecendo benefícios para brasileiras de classe média, que trabalham em setores acadêmicos em Los Angeles (Beserra, 2007), e trabalhadoras nos serviços públicos em Lisboa (Pinto 2004). Entretanto, os principais benefícios obtidos mediante a corporificação da sensualidade por mulheres que não trabalham na indústria do sexo estão relacionados, sobretudo, com o mercado matrimonial. Nesses casos, as mulheres combinam sensualidade com outros atributos, performando a imagem de esposas sensuais, doces, domésticas, dedicadas e ávidas por serem mães.

Esposos estadounidenses e dos países do Sul da Europa parecem perceber os relacionamentos com essas mulheres como uma oportunidade para recriar, em algum ponto, padrões tradicionais de masculinidade, com o tempero adicional de desfrutar de um estilo particular de sexualidade (Beserra, 2007; Assis, 2004; Piscitelli, 2005). Para as brasileiras, performar essa combinação de noções abre caminhos, às vezes estratégicos, para desejados casamentos. Essas uniões mistas às vezes expõem as mulheres a riscos, particularmente àquelas com menos recursos, sujeitas a um grau mais intenso de desigualdade e racismo. Entretanto, esses casamentos, que oferecem a principal via para a obtenção de vistos de residência no marco de políticas migratórias cada vez mais restritivas, são almejados por diversos motivos. Eles são particularmente valorizados como recursos simbólicos que contribuem a obter cidadania cultural (Ong, 1996) no exterior?

7 Na pesquisa sobre migrantes brasileiras que realizei na Itália (Piscitelli, 2007) o casamento representa mais do que a possibilidade de 'papéis'. Analisando os processos mediante os quais os migrantes procuram obter acesso à 'cidadania cultural', Aiwa Ong destaca a importância de práticas culturais e crenças nas negociações com critérios relativos à 'pertença' a um território e população nacional. O valor concedido pelas entrevistadas ao casamento mantém vinculações com essas idéias. Entre minhas entrevistadas, o casamento representa a materialização do sonho da ascensão social que, indo além da mobilidade em termos de classe social, envolve a ilusão da plena inclusão na Europa através da via legitimadora da inserção numa família italiana. 
Além disso, esses casamentos freqüentemente possibilitam alterar a posição social no Brasil, por diversas ações mediadas pelo poder econômico e tingidas pelo prestígio conferido por morar na Europa.

\section{Conclusão}

A história do feminismo está marcada pela procura de ferramentas analíticas para compreender as distribuições diferenciadas de poder que situam as mulheres em posições desiguais e, com base no conhecimento, modificar essas posições. Os conceitos de interseccionalidade e categorias articuladas fazem parte dessa história. Para além de situar a emergência desses conceitos, nesse texto procurei mostrar como, no momento atual, certas abordagens que trabalham com interseccionalidades oferecem recursos relevan- tes para compreender a produção de sujeitos na nova ordem global.

Nos contextos migratórios acima comentados, pensar nas articulações entre gênero, sexualidade, raça e etnicidade/ nacionalidade contribui para compreender as experiências das migrantes brasileiras. As interseções entre essas categorias dotam de sentido a percepção que se tem das brasileiras e as ações dessas mulheres, jogando com as interseções entre diferenças que elas corporificam nos cenários descritos.

A princípio, essas articulações situam essas migrantes em posições inferiorizadas, com efeitos concretos na inserção no mercado de trabalho. Ao mesmo tempo, as ambigüidades e contradições envolvendo esses processos de racialização/sexualização articulados a gênero e nacionalidade, abrem brechas para as negociações nesses contextos migratórios. Essas negociações só podem ter lugar se consideramos, à maneira de Brah, que as formas de categorização podem limitar, mas também abrem possibilidades para a agência.

\section{Referências}

AMOS, Valerie; PARMAR, Pratibha. Challenging Imperial Feminism, Feminist Review, n. 17, p. 3-19, 1984.

APARICIO, Frances R.; CHÁVEZ-SILVERMAN, Susana (ed.). Tropicalizations. Transcultural Representations of Latinidad. Hanover, University Press of New England, 1997.

APFELBAUM, Érika. "Domination". In: HIRATA, Helena; LABORIE, Françoise; DE DOARÉ, Hèléne; SENOTIER, Danièle (coord): Dictionnaire critique du féminisme. Presses Universitaires de France, Paris, 2000.

ASSIS, Gláucia de Oliveira. De Criciúma para o mundo: rearranjos familiares e de gênero nas vivências dos novos migrantes brasileiros. Phd Dissertation, Campinas, Unicamp, 2004.

AZEVEDO, Débora B. Brasileiros no exterior, Nota Técnica, Consultoria Legislativa da Área XVIII, Congresso Nacional, Brasília, 2004. URL (accessed in August, 2007. Disponível em: http://www2.camara.gov.br/internet/publicacoes/estnottec/tema3/pdf/2004_3518.pdf.

BACAZINN, Maxine; DILL, Bonnie Thornton. Theorizing difference from multiracial feminism. Feminist Studies, 22, n. 2, p. 321-331, 1996.

BEECHEY, Veronica. On Patriarchy. Feminist Review, n. 3, p. 66-83, 1979.

BESERRA, Bernadete. Sob a sombra de Carmen Miranda e do carnaval: brasileiras em Los Angeles, Cadernos Pagu 38, Campinas, Unicamp, 313-344, 2007.

BESSA, Karla. Pós-modernismo. Mimeo, IFCH, 1995.

BHAVBANI, Kum Kum. Feminism and Race. Oxford University Press, 2001.

BRAH, Avtar; PHOENIX, Ann. "Ain't I a Woman? Re- visting Intersectionality. Journal of International Women's Studies, 5, 3, may, p.75-86, 2004.

BRAH, Avtar. Diferença, diversidade, diferenciação, Cadernos Pagu 26, p.329-365, 2006.

BUTLER, Judith. Gender Trouble. New York, Routledge, 1990.

BUTLER, Judith. Undoing Gender, New York, Routledge, 2002.

CASA DO BRASIL EM LISBOA. "A $2^{\circ}$ vaga da imigração brasileira para Portugal (1998-2003): Estudo de opinião a imigrantes residentes nos distritos de Lisboa e Setúbal - Informação estatística e elementos de análise”. In: Imigração Brasileira em Portugal (ed.). Jorge Macaísta Malheiros, Lisboa, Alto Comissariado para a Imigração e Diálogo Intercultural, 227-245, 2007.

CAVALCANTI, Leonardo. "O protagonismo empresarial imigrante a partir de uma perspectiva de gênero: o caso das brasileiras nas cidades de Madri e Barcelona". Paper delivered at the Seminário Internacional Fazendo Gênero 7, Santa Catarina, 2006.

COSTA, Maria Tereza Paulino da. "Algumas considerações sobre imigrantes brasileiros na jurisdição do Consulado Brasileiro de Nova York". In: Brasileiros no exterior: Caminhos da Cidadania, ed. Bela Feldman-Bianco and Carlos Vianna, Campinas, Papirus. No prelo.

CRENSHAW, Kimberlé. Documento para o encontro de especialistas em aspectos da discriminação racial relativos ao gênero, Estudos feministas 1, p.171-189, 2002.

FIRESTONE, Shulamith. A dialética do sexo. Labor, Rio de Janeiro, 1976. 
FOUCAULT, Michel. História da sexualidade I: a vontade de saber. Rio de Janeiro, Graal, 1977.

GOLDMAN, EMA. Trafico de mujeres: y otros ensayos sobre feminismo, Buenos Aires, / Anagrama, 1977 [1917].

GRANT, Judith. Fundamental Feminism. Contesting the Core Concepts of Feminist Theory. Routledge, New York, 1993.

HALL, Stuart. Race, articulation and societies structured in dominance. In: HOUSTON Baerk; DIAWARA, Mantha; LINDEBORG, Ruth. Black British Cultural Studies, The University of Chicago Press, p. 16- 58, 1996.

HARAWAY, Donna. Simians, cyborgs, and women. The reinvention of nature. Routledge, New York, 1991.

HEINEN, Jacqueline. "Patriarcat". In: HIRATA, Helena; LABORIE, Françoise; DE DOARÉ, Hèléne; SENOTIER, Danièle (coord.): Dictionnaire critique du féminisme, Presses Universitaires de France, Paris, pp. 142-143, 2000. INSTITUTO NACIONAL DE ESTADÍSTICA, ESPAÑA. Base de datos INEbase, Año, URL: www.ine.es., 2006. INSTITUTO NACIONAL DE ESTADÍSTICA, ESPAÑA: Base de datos INEbase, Año 2005. URL: www. ine.es.

ISTITUTO NAZIONALE DE STATISTICA 2005: Gli stranieri in Italia: analisi dei dati censuari. In: : www.istat. it, 2005.

JUNCKS, Kátia Regina. La formación história de la clase obrera en la Barcelona del siglo XXI. Un pequeño diálogo con E.P. Thompson. Dissertation, Departamento de Humanidades, Universidad Autónoma de Barcelona, 2004.

MACHADO, Igor. "Introdução". In: Um Mar de Identidades a imigração brasileira em Portugal, (ed.) Igor José de Reno Machado, São Carlos, Edufscar, p. 7-19, 2006.

MAGNO, João. Relatório final da Comissão Parlamentar de Inquérito. Congresso Nacional, Brasília, Comissão Parlamentar Mista de Inquérito de Emigração, 2006.

MARTES, Ana Cristina Braga; SOARES, Weber. Remessas de recursos dos imigrantes. Estudos Avançados, v. 20, n. 57, p. 41-57, 2006.

MAYORGA, Claudia. "Identidade, Migração e Gênero: O caso de mulheres brasileiras prostitutas em Madrid". Paper delivered at the Seminário Internacional Fazendo Gênero 7, Santa Catarina, 2006.

McKLINTOCK, Anne. Imperial leather, Race, gender and sexuality in the colonial contest. Routledge, 1995.

McKLINTOCK, Anne. The Angel of Progress: Pitfalls of the term "pos-colonialism". Social text, n. 31/32, Third World and Post-Colonial Issues, p. 84-98, 1992.

MENEZES, Lená Medeiros de. "Movimentos e políticas migratórias em perspectiva histórica: um balanço do século XX”. In: Migrações Internacionais: Contribuições para Políticas (ed.). Mary Garcia Castro, 123-137. Brasília: Comissão Nacional de População e Desenvolvimento/CNPD, 2001. MESSIAS, DeAnne K. Hilfinger. Transnational Perspectives on Women's Domestic Work: Experiences of Brazilian Immigrants in the United States. Women and Health, v. 33, n. 1/2, p. 1-20, 2001.

MINISTÉRIO DA JUSTIÇA/NAÇÕES UNIDAS/ESCRITÓRIO CONTRA DROGAS E CRIME. Tráfico de
Seres Humanos no Brasil, Brasília, 2004.

MOHANTY, Chandra Talpade. Under Western Eyes. In: MOHANTY, Chandra Talpade; RUSSO, Ann; TORRES, Lourdes: Third World Women and the Politics of Feminism, Indiana University Press, p. 51-80, 1991.

NAGEL, Joane. Race, Ethnicity and Sexuality. Intimate Intersections, Forbidden Frontiers. Oxford, Oxford University Press, 2003.

OLIVEIRA, Adriana Capuano de. "Mulheres Imigrantes no Sul da Florida: Um estudo de caso revelando diferenças". Paper delivered at the Seminário Internacional Fazendo Gênero 7, Santa Catarina, 2006.

ONG, Aiwa. Cultural Citizenship as Subject-Making. Current Anthropology, v. 37, n. 5, Dec. p.737-762, 1996.

OVERING, Joanna. "Men Control Women? The Catch-22 in Gender Analysis", International Journal of Moral and Social Studies, v. 1. n. 2, p. 135-156, 1986.

PADILLA, Beatriz. Integração dos "imigrantes brasileiros recém-chegados" na sociedade portuguesa: problemas e possibilidades. Um mar de identidades, a imigração brasileira em Portugal (ed.). Igor José de Renó Machado, São Carlos, Edufscar, p. 19-42, 2006.

PINTO, Luciana Pontes. Mulheres brasileiras na mídia portuguesa, Cadernos Pagu, n. 23, cara, cor, corpo. Campinas, Unicamp, p. 229-257, 2004.

PISCITELLI, Adriana. On Gringos and Natives, Gender and Sexuality in the Context of International Sex Tourism, Vibrant - Virtual Brazilian Anthropology 1, p. 87-114. URL (accessed in June 2007). Disponível em:http://www. vibrant.org.br/portugues/artigos2004.htm, 2004.

PISCITELLI, Adriana. Intérêt et sentiment: migration de Brésiliennes em Italie dans le contexte du tourisme sexuel international. Migrations Societe; Le grand tournant: De l'emigration à l'immigration (Colloque de Cerisy). v. 17, n. 102, p. 105-125, 2005.

PISCITELLI, Adriana. Brasileiras na indústria transnacional do sexo, Nuevo Mundo Mundos Nuevos, 7. Disponível em http://nuevomundo.revues.org/document3744.html, 2007b.

PISCITELLI, Adriana. Shifting Boundaries: Sex and Money in the North-East of Brazil, Sexualities, v. 10, n. 4, p. 489-500, 2007.

PRINS, Baukje. Narrative accounts of origins: a Blind Spot in the Intersectional Approach? European Journal of Women's Studies, v. 13, n. 3, p. 277-290, 2006.

REITER, Rayna. Introduction. In: REITER, Rayna. Toward an Anthropology of Women. Monthly Review Press, New York, 1975.

RIOS-NETO, Eduardo. Managing migration: the Brazilian case. Belo Horizonte: UFMG/Cedeplar, 2005.

RUBIN, Gayle. "The traffic in Women: Notes on the 'Political Economy of Sex"'. In: REITER, Rayna. Toward an Anthropology of Women. Monthly Review Press, New York, 1975.

SCOTT, Joan. Gender and the politics of history. Columbia University Press, 1988.

SCOTT, Joan. A invisibilidade da experiência. Projeto His- 
tória. Cultura e Trabalho. PUC-SP. São Paulo, n. 16, fev/98, p. 297-327, 1998.

SECRETARIA NACIONAL DE JUSTIÇA. Pesquisas em Tráfico de Pessoas, parte 2, Relatório: Indícios de tráfico de pessoas no universo de deportadas e não admitidas que regressam ao Brasil via o aeroporto de Guarulhos, Brasília, Ministério da Justiça, 2005.

SECRETARIA NACIONAL DE JUSTIÇA. Relatório: Tráfico internacional de pessoas e tráfico de migrantes entre deportados(as) e não admitidos(as)que regressam ao Brasil via o aeroporto internacional de São Paulo, Brasília, Ministério da Justiça, 2007.

SERVIÇO DE ESTRANGEIROS E FRONTEIRAS (SEF). Estatísticas: População Estrangeira Residente em Portugal, por nacionalidade segundo o sexo, dados de
2005. Lisboa, 2006.

SEYFERTH, Giralda. Imigração no Brasil: os preceitos de exclusão. Com ciência, revista eletrônica de jornalismo científico, n. 16. Disponível em: www.comciencia.br/reportagens/ migracoes/migr19.htm (accessed in August, 2007), 2001. SHOHAT, Ella. Notes on the "Post-Colonial", Social Text n. 31/32, Third World and Post-Colonial Issues, p. 99-113, 1992.

STRATHERN, Marilyn. The Gender of the Gift. University of California Press, 1988.

ZINGAROPOLI, Silvia. n/d Intervista a Rosa Mendes, Tutela per le brasiliane in Italia. L'Associzaione donne brasiliane in Itália é stata fondata a Roma da um gruppo di immigrate brasiliane. Disponível em: http://www.musibrasil.net (accessed in May, 2004).

\section{Intersectionalities, Articulations and Experiences of Brazilian Migrants}

\section{Abstract}

In this text, I present some comments on the categories dealing with the multiple differentiations, which, articulating with those of gender, cross the social realm: the categories of articulation and/or intesectionalities. I also analyze the contents attributed to those concepts and make considerations on how they contribute I the analyses a relevant problem in contemporary Brazil: feminization of international migration. In the first part of the article, I situate those notions in the frame of the history of feminist thought. In the second, I consider how their use acquires distinct connotations in relation to conceptualization of differences and of the manners through which the power and agency operate. Finally I reflect on how those notions contribute to understand the integration of Brazilian female migrants in the global labor and marriage markets.

Keywords: intersectionalities; gender; feminism; migration; global labor market; marriage market.

Data de recebimento do artigo: 30-05-2008

Data de aprovação do artigo: 05-09-2008 